Article

\title{
Approach for Designing Context-Specific, Locally Owned Interventions to Reduce Postharvest Losses: Case Study on Tomato Value Chains in Nigeria
}

\author{
Christine Plaisier ${ }^{1, *}$, Milindi Sibomana ${ }^{2}$, Johannes van der Waal ${ }^{3}$, Luud Clercx ${ }^{3}$, \\ Coen P. A. van Wagenberg ${ }^{1}$ and Youri Dijkxhoorn ${ }^{1}$ \\ 1 Wageningen Economic Research, 2595 BM Den Haag, The Netherlands; \\ coen.vanwagenberg@wur.nl (C.P.A.v.W.); youri.dijkxhoorn@wur.nl (Y.D.) \\ 2 M.AGRO-SPEC Ltd., P.O. Box 6734 Kigali, Rwanda; sylversi@yahoo.co.uk \\ 3 AgroFair Projects B.V., 2991 LN Barendrecht, The Netherlands; \\ hans-willem.van.der.waal@AGROFAIR.NL (J.v.d.W.); Luud.clercx@agrofair.nl (L.C.) \\ * Correspondence: christine.plaisier@wur.nl; Tel.: +31-70-3358330
}

Received: 29 November 2018; Accepted: 31 December 2018; Published: 7 January 2019

\begin{abstract}
Development projects on interventions to reduce postharvest losses (PHL) are often implemented largely independently of the specific context and without sufficient adaptation to the needs of people who are supposed to use them. An approach is needed for the design and implementation of specific, locally owned interventions in development projects. Our approach is based on Participatory Development and includes Living Lab and World Cafés. We applied the approach in a case study on reducing PHL in tomato value chains in Nigeria. The approach consists of nine steps. After scoping the sector, selected value chain stakeholders (case: farmers, transporters, traders, retailers) were gathered in Living Lab workshops. In the workshop, participants analyzed the product, information, and monetary flows in their own value chain, identified causes for PHL, and selected potential interventions to reduce these (case: plastic crates instead of raffia baskets to transport tomatoes). Selected interventions were implemented, tested, and monitored in pilot projects with the workshop participants. This was followed by an evaluation workshop. At the end of the case study, $89 \%$ of participants bought crates to keep using them in their value chain. Our approach resulted in context-specific, locally owned interventions to reduce PHL in the case study on tomato value chains in Nigeria. Its application in other countries, commodities, or interventions is needed to determine the effectiveness of the approach in a broader scope.
\end{abstract}

Keywords: value chain development; participatory approach; context-specific interventions; behavioural change; postharvest losses; tomato; Nigeria; supply chain; raffia basket; plastic crate

\section{Introduction}

Feeding Africa's urban population is a task that is becoming ever more challenging. Currently, urban areas in Africa comprise of 472 million people. That number is expected to double over the next 25 years as more migrants are pushed into the cities from the countryside, with annual growth rates of up to $4 \%$ for the largest cities [1]. Good health and wellbeing, sustainable cities and communities, and responsible consumption and production are all relevant sustainable development goals (SDG) in this respect [2]. To ensure these SDGs are met, the provision of good-quality food in adequate quantities is of crucial importance. Much attention has been paid to the supply side of food by improving the yield and productivity of agricultural production. Less attention has been paid to the importance of optimal supply networks, which are the links between agricultural production and (urban) consumers. In such supply networks, a large amount of the food produced for human consumption is lost or 
wasted as a result of damage, rotting, pests, and diseases [3,4]. Reducing such so-called postharvest losses (PHL) is a key pathway to food and nutrition security in sub-Saharan Africa [5].

Many initiatives have been taken to reduce PHL in sub-Saharan Africa [5,6]. Development agencies, governments, non-governmental organizations, and private companies have been keen to invest in installations and equipment to improve supply networks, such as by putting in place cold stores and collective market structures. However, Ika [7] found that 50 to $64 \%$ of value chain development projects in Africa fail because of inadequate beneficiary needs analysis, poor stakeholder management, and overemphasis on financial and technical feasibility at the expense of social, cultural, environmental, and political feasibility. In other words, such projects suffer from a lack of ownership and insufficient adaptation of interventions to the needs of the people who were supposed to use them. Such projects have become "white elephants"- beautiful temporary gifts, but useless [8]. One cause for this is the fact that innovations to reduce PHL in sub-Saharan Africa were developed and tested without sufficient participation of local stakeholders [5]. Existing guides for value chain development are designed to implement interventions largely independently of the specific context, and insufficiently incorporate co-creation, co-testing, and co-analyzing of interventions with local stakeholders [9]. As a consequence, there is still a significant lack of adoption of the innovations presented, resulting in ever-present high postharvest losses observed across various agricultural value chains in Nigeria. Ideally, all actors, from producers to transporters and traders, are involved in problem identification, solution generation, pilot testing, and intervention calibration. This would improve the adoption potential of generated solutions. An approach is needed for the design of such context-specific and locally owned interventions to reduce PHL. This study aims to develop and test such an approach.

Our study follows the thinking of Participatory Development, which advocates the active participation of stakeholders in the decision-making process $[10,11]$. Participatory methods can enhance the uptake and sustainable use of new (technological) solutions [5]. In our approach for designing context-specific, locally owned interventions to reduce PHL, we included the Living Lab as a participatory process to co-create, co-test, and co-analyze the interventions with relevant value chain stakeholders. The Living Lab is a user-centered development concept with two essential elements, namely a real-life test and experimentation environment [12]. The Living Lab provides for a real-world setting, involving multiple stakeholders from multiple organizations, stages, or backgrounds, and their interaction. Application of the Living Lab results in users who are aware that they are co-involved in and co-owners of the innovation process [12]. The Living Lab helps create trust and commitment, which are prerequisites for sustainable and effective cooperation in supply chains [13].

We applied the approach to reducing PHL in a case study on reducing PHL in tomato value chains in Nigeria. Nigeria is the most populous country of sub-Saharan Africa, with an estimated population of about 190 million people. Nigeria is one of the leading producers of tomatoes in Africa. According to the statistics from the Food and Agricultural Organization of the United Nations, in 2016, Nigeria ranked number one in Africa in areas planted with tomatoes and number four in the world, and number 14 in production volume in the world. Tomatoes are an important vegetable in the local Nigerian cuisine, because they are used daily [14]. According to Adeoye et al. [15], over 90\% of studied consumers in the city of Ibadan in Nigeria purchase tomatoes in the urban market. Of these consumers, over $90 \%$ purchase fresh tomatoes. Compared to other developing countries in Africa, Nigeria lags behind in agricultural productivity development due to long periods of underinvestment in public infrastructure, such as roads, energy generation, and clean water supply [16]. Tomato supply chains are affected by a lack of investments in storage, packaging, transportation and marketing infrastructure, and are highly fragmented. Prior research has highlighted numerous problems in the tomato supply network in Nigeria, especially around PHL. Pre-consumer PHL range from an estimated 25\% [17] to as high as $50 \%[18,19]$. Some research suggested improvements to reduce PHL $[6,20,21]$. However, the results of these studies were often fragmented in time, space, and focus, and did not address the question on how to effectively test and embed suggested improvements in the value chain. Potential 
solutions need a strong support base across the value chain as Nigerian tomato value chains are often informal and fragmented, and lead firms or value chain captains are lacking.

This study's research aim was to develop an approach with which to design context-specific, locally owned interventions to reduce PHL. The remainder of this paper is structured as follows. In Section 2, we present the approach for designing and testing context-specific interventions to reduce PHL that are locally owned by all value chain actors. In Section 3, we present the results of the approach applied to the PHL in tomato value chains in Nigeria. Section 4 provides the discussion, and Section 5 the conclusions.

\section{Materials and Methods}

The approach for designing and testing context-specific interventions to reduce PHL, which are locally owned by all value chain actors (Figure 1) was developed based on consultations with an international and local research team and actors in the tomato value chain in Nigeria. The approach is based on Participatory Development, which actively includes stakeholders in the decision-making process [10,11]. In the approach, we applied Living Lab workshops [12] with a "World Café" setting [22]. The research team consisted of three Dutch, two Nigerian, and one Rwanda expert from development organizations with extensive experience in implementing solutions in developing countries, with three experts from Wageningen Economic Research with significant experience in value chain development and impact evaluation of such solutions, and three experts from Wageningen Food \& Biobased Research on PHL. The research team was supported by local enumerators for translation and monitoring the pilot projects. Members of the research team were involved in developing all steps of the approach. The actors in the tomato value chain were involved in steps 4 to 9 of the approach. The approach consists of nine steps, which are described below.

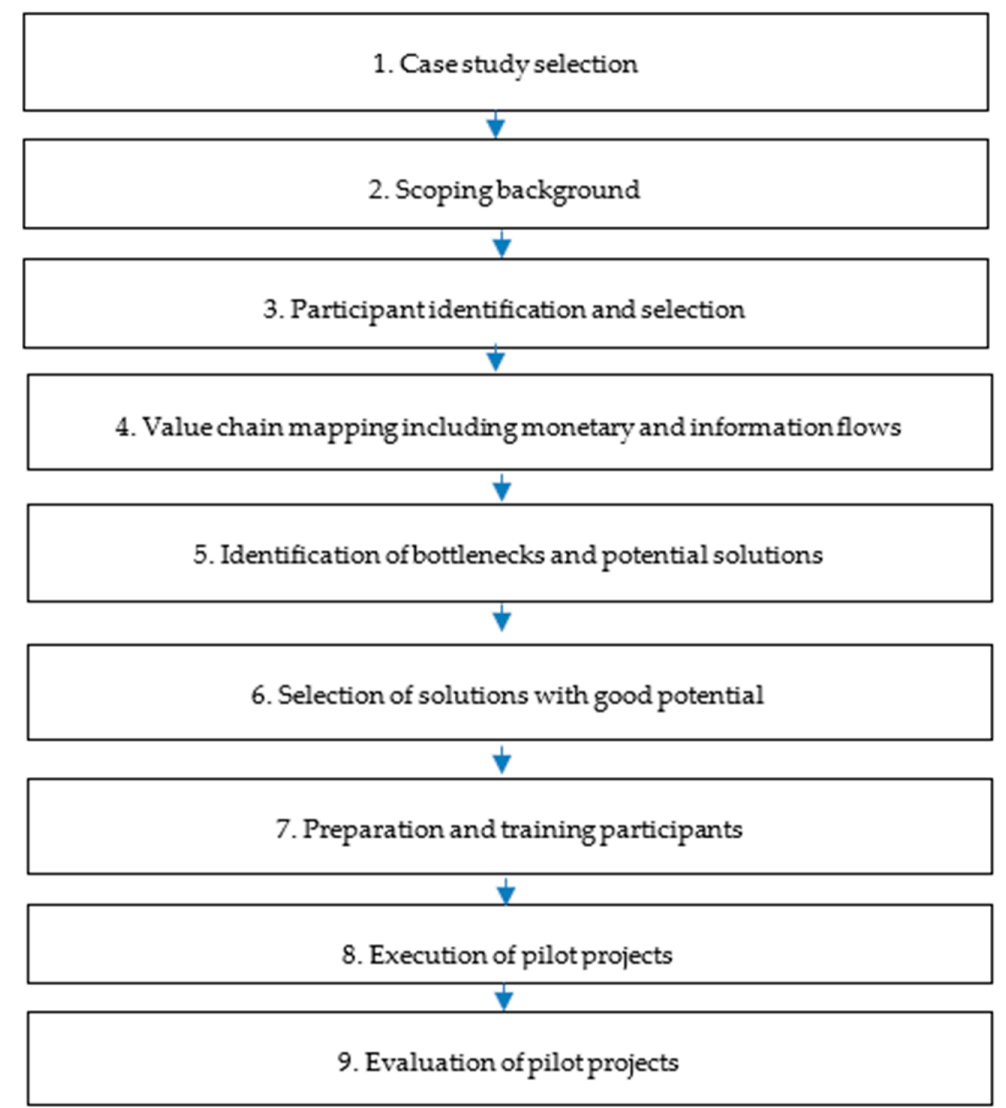

Figure 1. Approach for designing context-specific solutions to reduce postharvest losses, which are locally owned by all value chain actors. 


\subsection{Case Study Selection}

In Step 1, the case studies to be analyzed are defined. The product(s) and geographical region(s) of production and consumption are selected for which improvements in PHL are potentially viable. To this end, a literature review and or expert knowledge can be used.

\subsection{Scoping Background}

Step 2 of the approach consists of gathering in-depth background information on the PHL in the selected case studies from key value chain actors (such as producers, transporters, processors, traders, and retailers), and key informants from the government and other relevant organizations, e.g., development organizations. For example, this can be done through a scoping survey and interviews among the stakeholders. It addresses the general characteristics of the value chain actors (gender, age, education, and production), the value chain and marketing characteristics (purchase and sale points, payment moment, bargaining power, customer relationship) and the potential causes for PHL related to shelf life, tomato yield, and transport efficiency. The appropriate selection strategy of participants depends on the context and envisioned scope. Ideally, a random sampling strategy is applied with representation of the diversity participants of various value chain stages, production tiers, i.e., small to commercial farmers, single-vehicle to fleet hauliers, and wholesalers to retailers to determine the status quo in the different areas.

\subsection{Participant Identification and Selection}

In Step 3 of the approach, a limited number of value chain actors are selected for participation in Living Lab workshops and pilot projects. Potential participants represent all actors active in the value chain. Again, the appropriate selection strategy of participants depends on the context, envisioned scope, and the project period and timing, but the selection should be based on three criteria:

(1) Participants are active actors actually working in the value chain in at least one of the activities, such as production, transportation, processing, trading, or retailing;

(2) Participants are already trading with at least one other participant in the value chain;

(3) Participants are willing to implement potential innovations to reduce PHL and are committed to participate for the entire project trial.

\subsection{Value Chain Mapping Including Monetary and Information Flows}

In Step 4, the participants map their own value chain, including monetary and information flows. To this end, the participants are brought together in a Living Lab workshop. Living Lab workshops are especially suited when network partners, together with end-users need to develop innovation processes to address specific challenges [23]. Involvement of value chain actors in the problem contextualization and innovation development process is critical for the development of sustainable innovation solutions [24,25]. The Living Lab workshop also offers opportunities for informal contacts and thus helps to improve the bonds between the value chain actors. [26]. With Higgins and Klein [26], we believe that inviting the respective parties to engage in the Living Lab's real-world experiment is a promising option because they can be more willing to overcome established attitudes and obstacles, as long as it is "only" in an experimental setting. As such, it may enable the establishment of forums and supportive environments for innovators which can otherwise be stuck in existing adversarial relations, hierarchies, and traditional practices. The experimental setting also encourages a critical attitude and searching for creative solutions. Moreover, the Living Lab itself can give a symbolic meaning to the process of facilitating broader collective action. The Lab can signal commitment, momentum of change, and the opportunity to act and take charge of developments that are critical for the development of the participating parties.

In the Living Lab workshop, participants are grouped in round tables, with each table containing actors from each part of the chain, effectively forming a platform to engage on the different aspects of 
the value chain. This Living Lab workshop follows a structured approach in three stages. Stage 1 of the Living Lab workshop is a feedback and validation session discussing the outcomes of the scoping survey. In Stage 2, the participants map the connections in, and product flows through their own supply chain. This involves free mapping to show connections in the supply chain as perceived by the stakeholders and identification of points of tomato losses (hotspots) in the supply chain scheme. Participants are asked to brainstorm and identify all possible stakeholders and relations. Some work out a linear map, others a network map, with less or more detail. This exercise is useful to visualize and identify the players and relations in the chain. The final map is visualized on paper.

After mapping the supply chain, a depiction of monetary and information flows in the supply chain is created (Stage 3). Participants are asked to identify different inflows and outflows (or processes) of money, information, and tomato operations at the levels of farmers, hauliers, traders, and retailers, as the illustration or precision of the relations between the stakeholders of the chain.

In Stage 3, the participants together identify the main bottlenecks in their chains, as well as possible solutions (based on the maps and information flows depicted in the previous stages). The participants start with a broad approach in which every actor identifies the main problems in the chain. The problems can vary from lack of quality inputs, to the state of the road, to the institutional environment.

\subsection{Identification of Bottlenecks and Potential Solutions}

In Step 5, the main bottlenecks causing PHL and potential solutions for these bottlenecks are identified. Each group of participants identifies bottlenecks in their own value chain, considering the value chain map, and monetary and information flows identified in the previous step. Then, each group identifies possible solutions for each identified bottleneck.

The bottlenecks and potential solutions are presented in tabular form, per value chain actor and per link of the value chain. This is followed by a plenary session in which each group presents their results to all other groups. After the plenary session, a so-called "World Café" [22] is organized, in which participants from each group, except a reporter, move to another group to observe and discuss the bottlenecks and solutions of the other group. The café's ambience allows for a more relaxed and open conversation to take place. This type of conversation is a creative process for leading collaborative dialogue, sharing knowledge, and creating possibilities for action in groups of all sizes [27]. The environment is set up like a café, with paper-covered round tables. Participants are provided with pens, paper, and stickers and are encouraged to draw and record their conversations on the paper tablecloths or other materials to capture free-flowing ideas as they emerge. Participants discuss the issue at hand around their table, and they move to a new table at regular intervals. One participant (the table host) remains and summarizes the previous conversation to the newly arrived participants. By moving participants around the room, the conversations at each table are cross-fertilized with ideas from other tables. At the end of the process, the main ideas are summarized in a plenary session, and follow-up possibilities are discussed $[22,27,28]$. Members of the groups can indicate their preferences on the worksheets with material like stickers, pencils, symbols (for example, applying green dots for preferred solutions). The other groups review the worksheet and can also indicate their preference (e.g., with a blue dot). Participants then reconvene at their original group to revise their own bottlenecks and solutions. This results in a final list of bottlenecks and potential solutions for each group.

\subsection{Selection of Solutions with Good Potential}

In Step 6, participants identify the most promising solutions for application in pilot projects. Out of all the potential solutions portrayed, each group identifies the two most important bottlenecks in their own value chain and the two most viable potential solutions for these bottlenecks, which they could commit to testing in a pilot project. The potential solutions should be guided by a set of SMART criteria-i.e., the solutions should be Specific (what is included/excluded in the activities), 
Measurable (what is the envisaged result: how to measure), Achievable/Attractive (achievable within the scope of the project, in potential self-sustainable, is the solution attractive, what is the role division), Realistic (can we do it given the constraints), and Time-Specific (within the available timeframe and with milestones set).

Next in the second "World Café" set-up, each group receives the selected bottleneck-intervention combinations of another group. Each group votes for which of these bottleneck-intervention combinations is the most feasible. At the end of this activity, all votes for each bottleneck-intervention combination are added. The combinations with the most votes from all the groups are then selected to be implemented in pilot projects. The number of bottleneck-intervention combinations selected for pilot projects cannot be too large, because the participants will have to implement these and too many pilots implemented simultaneously could negatively affect the implementation.

\subsection{Preparation and Training Participants}

In Step 7 of the approach, all preparatory actions for the pilot projects are performed. This includes logistics, permissions, and any other organization needed before implementation, as well as training of the participants of the workshop on the implementation of the selected interventions and training of enumerators for evaluation of the impact of the solutions. When all logistics, hardware, and permissions are ready, an official kick-off workshop of approximately two days is organized to prepare the pilot projects with the value chain actors and the research team. In this workshop, all risks and potential challenges in the implementation of the pilot projects are discussed and anticipated for as much as possible. The participants design the appropriate starting and ending dates, the planning, timelines, and requirements, and again, all commit fully to the implementation. It is important that all agree on the set-up and planning and that the process is highly participatory. All should be given the opportunity to express their ideas and doubts, which enables a constructive discussion and customized design before the official take-off.

\subsection{Execution of Pilot Projects}

In Step 8, the value chain actors put the proposed solutions in practice and the local research team monitor the results of the intervention. To overcome the initial errors, doubts, and hiccups encountered along the way, it is important to have a local representative of the team available to coach all participants during the implementation period. This person must be able to reach all participants, be aware of the planning of each value chain, and able to monitor the processes. To monitor the extent to which the intervention solves the bottlenecks, an intervention-specific monitoring tool must be developed, and a local monitoring team should be established.

\subsection{Evaluation of Pilot Projects}

In Step 9, the research team, together with all participants, evaluates each pilot project and identified bottlenecks for continuation and upscaling. A workshop is organized to discuss and validate the results of the monitoring tool and the participants' personal experiences. Besides, participants are also challenged to outline the basic features for continuation of the project that would benefit all the value chain actors.

\section{Results}

\subsection{Case Study Selection}

In this study, we selected tomato value chains delivering from two regions in Nigeria with a tomato cultivation tradition to consumers in the urban areas of Lagos and Ibadan. The first group of value chains runs from farms in the South-West (Oyo, Osun, Ondo, and Katsina states) to the Mile 12 market in Lagos or Sasa market in Ibadan, with distances from 95 to $305 \mathrm{~km}$ from farm to retailer. The second group of value chains runs from farms in the North (Kano and Kaduna states) to retailers 
in Lagos (Okomaiko, Agege, Iyana Ipaja markets), with distances from 1085 to $1316 \mathrm{~km}$ from farm to retailer. With regard to this study, the sites and value chains of interest were chosen mainly because:

- The North-South value chain represents the highest volume of movement of tomatoes in the country, so it was important to understand dynamics there with regard to tomato losses and identify mitigation strategies;

- The South-West value chain also represents a secondarily high-volume tomato value chain in the country and with proximity to the highest consumption area, therefore this study would potentially uncover different tomato loss drivers, which may also result in different loss mitigation strategies which could be just as effective.

\subsection{Scoping Background}

Scoping surveys were held with actors from the supply chains from both regions. In the South-West, actor-specific scoping surveys were conducted among 48 farmers, 44 transporters, and 48 traders/retailers. The survey for traders/retailers was performed on the largest markets in the area, Sasa and Mile 12, which were the major end markets for the supply chain of tomatoes. In the North, the scoping surveys were conducted among 151 farmers, 89 transporters, and 109 traders/retailers.

Survey participants were randomly selected after the researchers had "followed the chain", which means that in an initial visit (prior to survey execution), the researchers had interviews with various actors in all parts of the supply chain in the areas of interest, e.g., the market (traders, retailers, wholesalers), farmer groups, and individual farmers who often supplied these markets (or supply other market actors), as well as hauliers who transported fresh produce (including tomatoes). These initial meetings enabled identification of the chain structure and networks, which enabled the research team to have access to participants who were later selected for the survey.

Simple random sampling and a structured questionnaire was employed as per [20,29]. The main criteria for participants in the survey was that they had to be involved commercially in the tomato chain regardless of level-in other words, small, medium, or large-scale growers, traders, or hauliers had to be involved directly in growing, transporting, or selling the product.

Limitations in the sampling methodology are acknowledged, and this technique was chosen primarily to give the researchers insight into the status quo of the tomato value chain in Nigeria, which would be compared to the outcomes of similar, more in-depth studies, e.g., by the Growth and Employment in States- Wholesale and Retail sector project (GEMS4) [20,29]. Similar to these studies, the data was analyzed using descriptive statistics, such as frequency counts and percentages. The software IBM SPSS Statistics version 17 (International Business Machines Corporation, New York, USA) was used for data analysis. Furthermore, validation of these results were to be done in a workshop setting where in-depth questions and discussions would allow the researchers more perspective into the different value chains. The workshop participants, as described in the next section, were not limited to scoping survey participants only.

Table 1 provides the general characteristics of the survey respondents, Table 2 the chain and marketing characteristics of the tomato value chains of the respondents, and Table 3 the potential causes for PHL in these tomato value chains mentioned by the respondents. The majority of respondents were male, a member of an association (either producer, transporter, or trader), and used raffia baskets as packaging material. This is similar to the results reported by $[20,29]$. The majority of transactions took place at the farm gate, collection centers, or markets. Poor infrastructure conditions, unsuitable tomato varieties, and poor postharvest handling were identified as critical drivers of PHL for farmers, and transporters were more concerned with poor infrastructure conditions, roadblocks, and poor postharvest handling. In both regions, limited postharvest infrastructure and unsuitable tomato varieties were identified as critical drivers of PHL for farmers, while traders were more concerned with poor transportation conditions. The challenges highlighted from these activities are consistent with earlier findings published by [19]. This served as an indication that the sampling method was effective enough to broadly capture the state of the tomato value chain in Nigeria, which was the aim of this step. 
Table 1. General characteristics of the respondents to a survey in tomato value chains from the South-West and North of Nigeria to the urban centers of Lagos and Ibadan held in 2017.

\begin{tabular}{|c|c|c|c|c|c|c|c|}
\hline \multirow[b]{2}{*}{ Characteristic } & \multirow[b]{2}{*}{ Option } & \multicolumn{3}{|c|}{ South-West } & \multicolumn{3}{|c|}{ North } \\
\hline & & $\begin{array}{c}\text { Producer } \\
(n=48)\end{array}$ & $\begin{array}{c}\text { Transporter } \\
(n=44)\end{array}$ & $\begin{array}{c}\text { Trader/Retailer } \\
\quad(n=48)\end{array}$ & $\begin{array}{l}\text { Producer } \\
(n=151)\end{array}$ & $\begin{array}{c}\text { Transporter } \\
(n=89)\end{array}$ & $\begin{array}{c}\text { Trader/Retailer } \\
\quad(n=109)\end{array}$ \\
\hline Gender (\%) & Male & 85 & 100 & 55 & 100 & 100 & 99 \\
\hline \multirow{4}{*}{ Education (\%) } & Primary school (in)complete & 23 & 46 & 52 & 32 & 28 & 25 \\
\hline & Secondary school (in)complete & 46 & 48 & 43 & 34 & 44 & 24 \\
\hline & Arabic school & & 2 & & 72 & 45 & 74 \\
\hline & Higher education & 32 & 5 & 7 & 4 & 10 & 11 \\
\hline \multirow{3}{*}{ Age (\%) } & $25-35$ years & 28 & 23 & 27 & 40 & 36 & 37 \\
\hline & $36-45$ years & 24 & 57 & 64 & 39 & 60 & 38 \\
\hline & $>45$ years & 48 & 43 & 9 & 21 & 3 & 24 \\
\hline $\begin{array}{c}\text { Member of } \\
\text { association (\%) }\end{array}$ & Yes & 92 & 85 & 72 & 64 & 60 & 77 \\
\hline \multirow{8}{*}{$\begin{array}{l}\text { Main function of } \\
\text { association }(\%)^{1}\end{array}$} & Information and training & 73 & & 42 & & & \\
\hline & Seeds and other inputs & 56 & & & & & \\
\hline & Sales & 46 & & & & & \\
\hline & Government liaison & & 45 & 31 & & & \\
\hline & Transport regulations & & 41 & & & & \\
\hline & (Off)loading coordination & & 41 & & & & \\
\hline & Collect Levies & & & 23 & & & \\
\hline & Price setting & & & 19 & & & \\
\hline \multirow{4}{*}{$\begin{array}{c}\text { Packaging } \\
\text { material (\%) }{ }^{1}\end{array}$} & Raffia basket & 63 & 100 & 90 & 102 & 97 & 100 \\
\hline & Sack & 2 & 100 & & 2 & 3 & \\
\hline & Crate & 13 & 8 & & 1 & 3 & \\
\hline & Mixed/other & 6 & 2 & 10 & & 4 & \\
\hline \multirow{3}{*}{$\begin{array}{c}\text { Tomato Growing } \\
\text { Experience }(\%)\end{array}$} & $1-3$ years & 35 & & & 13 & & \\
\hline & $3-10$ years & 28 & & & 53 & & \\
\hline & $>10$ years & 37 & & & 34 & & \\
\hline \multirow{2}{*}{$\begin{array}{l}\text { Tomato land } \\
\text { size (ha) }\end{array}$} & Wet season & 2 & & & 3 & & \\
\hline & Dry season & 1.2 & & & 2.7 & & \\
\hline \multirow{2}{*}{$\begin{array}{c}\text { Productivity } \\
\text { (kg/ha) }\end{array}$} & Wet season & 3523 & & & 10,455 & & \\
\hline & Dry season & 4838 & & & 14,698 & & \\
\hline \multirow{6}{*}{$\begin{array}{c}\text { Tomato variety } \\
\text { used }(\%)\end{array}$} & Hybrid-Padma F1 & 43 & & & & & \\
\hline & Carrot-Open-pollinated variety & 30 & & & & & \\
\hline & UC82B-Open-pollinated variety & & & & 72 & & \\
\hline & Roma vf-Open-pollinated variety & & & & 21 & & \\
\hline & Rio-Open-pollinated variety & & & & 7 & & \\
\hline & Other & 27 & & & & & \\
\hline
\end{tabular}


Table 1. Cont.

\begin{tabular}{|c|c|c|c|c|c|c|c|}
\hline \multirow[b]{2}{*}{ Characteristic } & \multirow[b]{2}{*}{ Option } & \multicolumn{3}{|c|}{ South-West } & \multicolumn{3}{|c|}{ North } \\
\hline & & $\begin{array}{c}\text { Producer } \\
(n=48)\end{array}$ & $\begin{array}{c}\text { Transporter } \\
(n=44)\end{array}$ & $\begin{array}{c}\text { Trader/Retailer } \\
\quad(n=48)\end{array}$ & $\begin{array}{l}\text { Producer } \\
(n=151)\end{array}$ & $\begin{array}{c}\text { Transporter } \\
(n=89)\end{array}$ & $\begin{array}{c}\text { Trader/Retailer } \\
(n=109)\end{array}$ \\
\hline Truck/car & Owns the truck & & 41 & & & 24 & \\
\hline ownership (\%) ${ }^{1}$ & Driver of individual/company & & 85 & & & 76 & \\
\hline Truck/car & Empty & & 95 & & & 17 & \\
\hline backhaul (\%) & Loaded & & 5 & & & 83 & \\
\hline
\end{tabular}

${ }^{1}$ Multiple answers were possible, so the sum can exceed $100 \%$

Table 2. Value chain and marketing characteristics of tomato value chains from the South-West and North of Nigeria to the urban centers of Lagos and Ibadan, mentioned by respondents in response to a survey held in 2017.

\begin{tabular}{|c|c|c|c|c|c|c|c|}
\hline \multirow[b]{2}{*}{ Characteristic } & \multirow[b]{2}{*}{ Option } & \multicolumn{3}{|c|}{ South-West } & \multicolumn{3}{|c|}{ North } \\
\hline & & $\begin{array}{l}\text { Producer } \\
(n=48)\end{array}$ & $\begin{array}{c}\text { Transporter } \\
(n=44)\end{array}$ & $\begin{array}{c}\text { Trader/Retailer } \\
(n=48)\end{array}$ & $\begin{array}{l}\text { Producer } \\
(n=151)\end{array}$ & $\begin{array}{c}\text { Transporter } \\
(n=89)\end{array}$ & $\begin{array}{c}\text { Trader/Retailer } \\
(n=109)\end{array}$ \\
\hline \multirow{5}{*}{$\begin{array}{l}\text { Farmer sale point, } \\
\text { transporter/trader } / \text { retailer } \\
\text { collection point }(\%)^{1}\end{array}$} & Market & 56 & & & 42 & & \\
\hline & Collection Centre & 44 & 70 & 50 & 58 & 92 & 51 \\
\hline & Farm gate & 25 & 50 & & 27 & 43 & \\
\hline & Trader & & & 17 & & & 14 \\
\hline & Other & & & 10 & & & 3 \\
\hline Bargaining power $(\%)$ & Yes & 72 & & & 52 & & \\
\hline $\begin{array}{c}\text { Knowledge of in-transit } \\
\text { losses }(\%)\end{array}$ & Yes & 36 & & & 43 & & \\
\hline $\begin{array}{l}\text { Market information } \\
\text { knowledge }(\%)\end{array}$ & Yes & 72 & & & 87 & & \\
\hline \multirow{4}{*}{$\begin{array}{l}\text { Moment buyer pays } \\
\text { farmer }(\%)^{1}\end{array}$} & In advance & 2 & & & 9 & & \\
\hline & At sale (farm gate) & 88 & & & 56 & & \\
\hline & Afterwards & 6 & & & 15 & & \\
\hline & Combination & 11 & & & 20 & & \\
\hline \multirow{2}{*}{ Trader customer $(\%)$} & Wholesale & & & 71 & & & 56 \\
\hline & Retail & & & 29 & & & 44 \\
\hline \multirow{2}{*}{$\begin{array}{c}\text { Trader } / \text { retailer } \\
\text { customer base }(\%){ }^{1}\end{array}$} & Fixed & & & 60 & & & 54 \\
\hline & Changing & & & 40 & & & 92 \\
\hline
\end{tabular}

${ }^{1}$ Multiple answers were possible, so the sum can exceed $100 \%$. 
Table 3. Potential causes for postharvest losses in tomato value chains from the South-West and North of Nigeria to the urban centers of Lagos and Ibadan, mentioned by respondents in response to a survey held in 2017.

\begin{tabular}{|c|c|c|c|c|c|}
\hline \multirow[b]{2}{*}{ Characteristic } & \multirow[b]{2}{*}{ Option } & \multicolumn{2}{|c|}{ South-West } & \multicolumn{2}{|c|}{ North } \\
\hline & & $\begin{array}{l}\text { Producer } \\
(n=48)\end{array}$ & $\begin{array}{l}\text { Transprter } \\
(n=44)\end{array}$ & $\begin{array}{l}\text { Producer } \\
(n=151)\end{array}$ & $\begin{array}{c}\text { Transporter } \\
(n=89)\end{array}$ \\
\hline \multirow{9}{*}{$\begin{array}{c}\text { Shelf life } \\
\text { limiting } \\
\text { factors (\%) }\end{array}$} & Lack of/poor infrastructure & 33 & 58 & 44 & 49 \\
\hline & Unsuitable/poor variety & 23 & 38 & 38 & 52 \\
\hline & Poor (post-)harvest handling & 17 & 44 & 61 & 26 \\
\hline & Poor packaging & 19 & 29 & 15 & 29 \\
\hline & Low level/lack of technology and skills & 23 & & 33 & \\
\hline & Poor market facilities & & 33 & & 35 \\
\hline & Lack of market incentives & 17 & & 35 & \\
\hline & Harvest at very ripe stage & 17 & & 15 & \\
\hline & Other & & 29 & 13 & 8 \\
\hline \multirow{7}{*}{$\begin{array}{l}\text { Factors } \\
\text { affecting } \\
\text { tomato } \\
\text { yield }(\%)^{1}\end{array}$} & Pests and diseases & 75 & & 70 & \\
\hline & Excess rainfall & 44 & & 17 & \\
\hline & Drought/lack of water & 23 & & 29 & \\
\hline & Bad seed & 21 & & 29 & \\
\hline & Low level/lack of technology and skills & 17 & & 23 & \\
\hline & Lack of fertilizer & 13 & & 43 & \\
\hline & High temperature & & & 26 & \\
\hline \multirow{7}{*}{$\begin{array}{l}\text { Factors limiting } \\
\text { efficient } \\
\text { transport (\%) }\end{array}$} & Road blocks/delays & & 84 & & 81 \\
\hline & Poor/lack of infrastructure & & 80 & & 88 \\
\hline & Road congestion & & 59 & & 29 \\
\hline & Vehicle breakdown & & 43 & & 35 \\
\hline & Delays in (off)loading & & 11 & & 16 \\
\hline & Poor market infrastructure & & 9 & & 10 \\
\hline & Other & 14 & 14 & & 11 \\
\hline
\end{tabular}

${ }^{1}$ Multiple answers were possible, so the sum can exceed $100 \%$.

\subsection{Selection of Participants}

Participants were selected from the value chain actors that participated in the scoping survey (for the simple random sampling strategy of the survey respondents, see Section 2.2). The following criteria were applied to select and invite the participants of the workshop (see also Section 2.3): (i) Participants are active actors actually working in the value chain in at least one of the activities, such as production, transportation, processing, trading, or retailing; (ii) participants are already trading with at least one other participant in the value chain; and (iii) participants are willing to implement potential innovations to reduce postharvest losses, and commit to participate for the entire project period.

In the North, 27 value chain actors (15 farmers, 4 transporters, 5 traders, 3 retailers) were selected, and in the South-West, 24 were selected ( 8 farmers, 4 transporters, 6 traders, 6 retailers). Budgetary constraints limited the number of participants and number of workshops.

\subsection{Value Chain Mapping Including Monetary and Information Flows}

Two Living Lab workshops were held, one in Ibadan (South-West) and one in Kano (North). Each workshop lasted for two days. The Living Lab workshops started with a plenary session, discussing and validating the outcomes of the scoping surveys. In both workshops, five groups of participants were established. Each group represented a value chain and contained at least one farmer, one transporter, one trader, and one retailer. Local enumerators were present to guide participants through the assignments and to assist and translate where needed.

In the South-West, two groups indicated that product flow was from producers to the traders via transporters, while one group specified that producers were directly connected with retailers and traders without transporters. Farmers in the South-West have more interaction with the end markets, and take their own produce to the market or bear the cost of transportation to the market. This could be 
related to the shorter distance between production and the market in the South-West $(100-200 \mathrm{~km})$ compared to the North $(800-1,200 \mathrm{~km})$. In contrast to the South-West, aggregation markets were present in the North.

Monetary and information flows were generally similar in the South-West and North. A difference is that farmers and traders in the South-West indicated to have more expenses compared to those in the North. This could be an actual reality, or it may be that farmers and traders in the South-West were more aware of their outgoing expenditures. Bribes to police or security officials was noted more frequently in the South-West value chain compared to the Northern value chain. With regard to information flows, it was evident that actors in the North were more active in sharing information on supply-demand variations in the market, i.e., glut-scarcity periods.

\subsection{Identification of Bottlenecks and Potential Solutions}

The main bottlenecks causing PHL were the occurrence of pests and diseases, low access to (quality) inputs, poor road infrastructure, inappropriate harvest and postharvest handling practices, and the seasonality of the production system. Access to good quality and unadulterated insecticides and quality control of this by the government were identified as solutions to prevent losses due to pests and diseases. Access to good quality seed from seed companies at an affordable cost and from an easy to access site to their communities were identified as a solution to prevent losses due to low access to (quality) inputs. As a specific problem, participants from the South-West mentioned the challenge caused by herdsmen moving their animals across tomato fields. In the North, a suggested solution for delivery delays was reduction of checkpoints on the road. However, the same actors also acknowledged insecurity as an issue and recommended increased police presence on the roads. In the North, participants identified bad harvesting practices as an important factor contributing to losses, with a recommendation for training on harvesting and handling of tomatoes on the farm to reduce losses. In the South-West, participants mentioned the hours of exposure which harvested tomatoes had to high temperatures while waiting for the transporter, as an important possible cause of PHL. Significant reduction in quality occurred during transportation, which attributed to the use of raffia baskets and which were often overloaded and squeezed during stowage, resulting in mechanical damage. A proposed solution to this was the use of plastic crates. The seasonal production with a glut period was identified in both regions as an issue, although on-site engagement with farmers showed that it was a more dominant challenge in the North. Participants in the North indicated that managing product flows during the glut and scarcity periods could be an opportunity for improving efficiency and reducing tomato loss in this chain.

\subsection{Selection of Solutions with Good Potential}

In each region, the participants mentioned and agreed upon two solutions to be tested in a pilot project by the participants. In this paper, we will only present the solution selected in both regions, which is sufficient to show the functioning of the approach. The solution agreed upon was the transport of tomatoes in returnable plastic crates instead of in the usual raffia baskets to reduce losses.

The solution not only had a $100 \%$ support base among the participants, but it also met the criteria of being specific, measurable, achievable (and affordable), realistic, and possible within the time boundaries of the project.

\subsection{Preparation of Pilot Projects}

The project team purchased the necessary materials and equipment, such as 600 plastic crates, and 15 analogue and 5 digital scales for weighing. A tool to measure and monitor the impact of the plastic crates on PHL both in weight and in quality was developed. Local enumerators were recruited for applying the measurement tool and monitoring the pilot projects during execution. 
In each region, all participants and local enumerators were gathered in a two-day workshop to design and implement the plan for each solution, and to train the participants on the use of the solutions and on the tool to measure the impact of the solutions. In the South-West, 24 value chain actors and five local enumerators participated, and in the North, 27 value chain actors and four local enumerators took part. Per value chain and region, the participants designed an implementation plan which included a start and end date, responsibilities, tasks, and roles of each value chain actor, and the organization and logistics of the pilot project adapted to the local situation. Many issues and concerns were raised, such as the amount of tomatoes which were to be in a crate compared to the raffia baskets (as tomato amounts are measured in baskets), price-setting, the returning of crates, and payment for the transporter (payment per item carried). During the workshop, participants and local enumerators could familiarize themselves with the plastic crates, and they were provided with tomatoes, crates, baskets, and scales to understand how they should be comparing them to the raffia baskets in terms of handling, packing, weighing, and pricing. A draft version of the measurement tool was discussed with all participants and local enumerators and customized to ensure it was applicable to the local situation. For example, the quality grades in the measurement tool were aligned with the actual quality grades used in the value chain. In the South-West, three quality grades, A, B, and C, were used, whereas in the North, an additional grade, D was used. Points of weight measurement in the value chain were at the farm directly after harvest, at the farm just before transport, at arrival at the wholesale market, at the wholesale market just before leaving, and at arrival on the retail market. The tomatoes were only graded on quality at the first and last point of measurement to minimize disturbance. Batches of tomatoes were divided over crates and baskets and moved in the same transport vehicle to ensure similar conditions. The crates and baskets were marked at the farm, and these were followed in person throughout the value chain by the local enumerators. During the workshop, all participants and local enumerators received detailed training on the final measurement tool.

\subsection{Execution of Pilot Projects}

The pilot project on plastic crates in the South-West was conducted in December 2017 and in the North from February-March 2018. The plastic crates were tested compared to the conventional raffia baskets as a control. Tomatoes were collected from five farms in the South-West and three farms in the North on two separate days within a two-week period. Handling of the tomatoes was done as closely as possible to the normal situation in all links of the value chain. At farm level, tomatoes were sorted as usual by the farm workers during harvesting. Rotten or heavily damaged tomatoes were left on the field. After the enumerators weighed and graded the harvest, part of the harvested tomatoes were stacked in crates and the rest in baskets. It was ensured that quality grades were divided equally over crates and baskets. Any further preparation for the market until pickup by a transporter was done as usual. In some cases, the tomatoes were waiting for various hours. Before the actual loading took place, the tomatoes were weighed again to identify possible losses. The tomatoes were transported to the wholesale markets, in cars, small vans, and buses in the South-West and in large lorries in the North. At the market, the crates and raffia baskets were weighed again. In most cases, the tomatoes arrived around midnight at the market and were bought by the retailers in the early morning. Just before the retailers collected the tomatoes, they were weighed again to identify any possible weight loss. At arrival on the retail market, the tomatoes in both crates and baskets were weighed and graded using the same grades as used on the farm level.

\subsection{Evaluation of Pilot Projects}

Members of the project team analyzed the data collected with the measurement tool [30]. Crates were found to outperform baskets in both regions. Weight loss was between 5 and $12 \%$ lower with crates than with baskets. Similarly, the loss in best-quality A-grade tomatoes was between 16 and $20 \%$ lower with crates than with baskets. Here, we do not present further details on the PHL results that were measured in the pilot project, because the aim of this paper is to present the approach 
for designing context-specific interventions owned by local value chain actors. The details on the PHL results can be found in [30]. The results were discussed and presented in two-day evaluation workshops with the participating actors, one in the South-West and one in the North. All participants were invited to evaluate the pilot projects, and were guided with group assignments to facilitate the evaluation of their experiences and to ensure that all participants could express themselves. Value chain actors were also challenged to outline the basic components of a business plan that would benefit all the value chain actors.

All participants were happy to find the reduction in losses by using crates instead of baskets. Each value chain actor mentioned the benefits of crate use at each specific stage in the chain. Overall, retailers and traders stated a preference for tomatoes transported in crates compared to raffia baskets, because of the increased volume of quality products. Transporters appreciated the ease associated with loading and offloading crates, and it also meant that the wooden planks and grass thatch used to separate two layers of raffia baskets during transport were not needed anymore. Farmers appreciated the ease of postharvest handling and the stacking possibilities of crates. All participants mentioned that the introduction of plastic crates could also contribute to the standardization of measuring units and the introduction of scales-each crate had the same size and could contain around $23 \mathrm{~kg}$ of tomatoes. At the time, several types and sizes of baskets were being used, and weighing scales were not used. A large majority of participants (87\%) preferred plastic crates to raffia baskets. Only $9 \%$ of participants preferred raffia baskets over plastic crates, and this was specifically for the greater level of convenience in returning from the retailer to the farm and stocking in a car. The remaining $4 \%$ of participants did not have a preference. After the evaluation pilot, the participants were provided the opportunity to purchase the plastic crates against half the price of a new crate. $67 \%$ of the participants bought the plastic crates they were using during the pilot, and $22 \%$ bought not only the crates used in the pilot but also some additional ones. This indicates a high adoption rate of the implemented intervention with plastic crates, and shows that it was a good fit for the local context.

In the final oral evaluation session, all participants expressed their appreciation of the approach applied. According to the participants, the design of the project helped them to overcome their initial skepticism, and to build trust in the innovation itself and in their co-value chain members. They were proud to be part of a community of change by acting and taking charge of an important developmental change.

However, the evaluation workshops also revealed several challenges and hiccups. The participants identified bottlenecks, which needed attention before upscaling could take place. Because of the current structure and organization of the value chain, not all actors could benefit equally. Retailers and traders had most of the financial gains. Most farmers did not benefit from the increased value of the tomatoes transported in crates, because pricing between farmer and trader occurred at the farm before transportation in the majority of cases. Transporters could even have a lower income, because they were paid per item and the transporter carried less items when transporting the larger and rigid crates compared to the smaller and more flexible baskets. Another challenge mentioned was the returning of the empty crates. In addition, no common agreement was reached on which actor(s) should purchase and own the crates and how this ownership could be protected. Crates are more expensive than baskets, but should last up to five years instead of one year. A final challenge was found in setting prices, because at the time, pricing was based on the size of a raffia basket and not on the weight of the content. The benefit of reduced losses was not totally reflected in a higher price when scales were not used, and price was set on the size of packing material.

\section{Discussion}

This paper presents an approach for designing context-specific interventions owned by local value chain actors. The approach was applied to develop an intervention to improve food security by reducing PHL in the tomato value chain in Nigeria. The approach considers contextual and cultural factors by actively involving value chain stakeholders working together to design an intervention. 
This solved potential problems which can occur in top-down initiatives following a technical-rational project management approach, as put forward by Ika [7] and Robinson and Torvik [8]. Although many guides for value chain development include some value chain actor participation to design interventions, most guides result in interventions implemented largely independently of the specific context, due to insufficient co-creation, co-testing, and co-analyzing of potential interventions with value chain stakeholders [9]. Especially in a value chain such as the tomato value chain in Nigeria, with a low level of governance and fragmented, undifferentiated local markets, active participation is needed to reach sustainable interventions owned by value chain actors. Potential solutions are taken off the drawing board and trialed in practice, testing both the technical feasibility of potential interventions and how the interventions are embedded in the business models of existing value networks. As such, our approach ensures the support base, commitment, and ownership of participants, which are crucial conditions for sustainable and effective development interventions aiming at a certain change. The Living Lab and World Café which were set up also stimulated trust among and between the participants, i.e., trust in the intervention itself but also in their peers, which were the other actors in their value chain.

However, this approach also has its limitations; it is relatively resource-intensive in terms of financial and human resources, and the Living Lab and World Café only allowed for a limited number of participants. The whole approach is also time-consuming.

The results of the pilot projects in the case study in Nigeria showed that the PHL were lower for tomatoes transported in plastic crates compared to those transported in raffia baskets, and that the percentage of good-quality tomatoes was higher when transported in plastic crates than in baskets. In an experiment which simulated transport, [31] also found that the mechanical damage to tomatoes resulting from impact and vibration was lower when using plastic crates compared to when using raffia baskets. The majority of the pilot project participants were convinced of the benefits of using crates instead of baskets, and experienced actual financial gains when using crates. This indicates that the application of our approach to reduce PHL in tomato value chains in Nigeria resulted in context-specific interventions that were owned by the pilot project participants.

Our approach resulted in a context-specific intervention owned by the local value chain actors who participated in the pilot projects. Ownership of an intervention in a pilot project is a first step for improvement of the efficiency and effectiveness in all tomato value chains in Nigeria. The pilot project participants are only a small group of all actors active in the tomato sector in Nigeria, and tomato consumers were also not incorporated. Several challenges for a broader implementation of the plastic crates in tomato value chains in Nigeria were identified, alongside the following issues: (i) Investment in and ownership of the crates; (ii) an effective crate-returning system; (iii) distribution of the financial benefits between value chain actors; (iv) pricing of transactions in the value chain; and (v) lack of using scales and factual measures to define the price. When upscaling the pilot project in our case study to national Nigerian level, the increase in tomato availability and increase in quality requires a food system approach to analyze the national impact. This analysis should include the different roles and reactions to these increases in the different value chain actors, consumers of all income levels, and other stakeholders. At national level, new governance mechanisms might be needed in tomato value chains, such as producer, trader, or transporter networks or associations, chain leadership development, or third parties with sufficient financial and organizational strength for the acquisition and leasing of crates and weighing scales.

We developed the approach for context-specific, locally owned interventions to reduce PHL and applied it in a case study on reducing PHL in tomato value chains in Nigeria by introducing plastic crates to transport the tomatoes. In this case study, the purchase of the crates by the value chain participants in the study after the pilot projects showed that these stakeholders intended to use the crates after the project had finished. Application of the approach to reduce PHL in other countries or commodities or in other interventions to improve food and nutrition security is required to also determine its effectiveness in a broader scope of development projects. 


\section{Conclusions}

This study provided an approach for designing, implementing, and testing context-specific interventions to reduce PHL with local value chain actors. In a Living Lab workshop with World Cafés, value chain actors together analyzed their own value chain and identified bottlenecks and potential interventions to solve each bottleneck. The most promising bottleneck intervention combination was tested in pilot projects, i.e., replacing the raffia baskets with plastic crates during tomato transport. The vast majority of pilot project participants in the case study of PHL in the tomato value chain in Nigeria indicated a preference of plastic crates to raffia baskets and bought crates after the project finished. This shows that the approach was effective in designing a context-specific, locally owned intervention. Application in other countries, commodities, or interventions is recommended to determine the effectiveness of the approach in a broader scope.

Author Contributions: C.P. facilitator living lab workshops and field work coordination. J.v.d.W. inception phase and contextual study. L.C. and C.P.A.v.W.: Project Management. M.S.: facilitator living lab workshops and data analyst and reporter survey. Y.D.: postharvest losses protocol design and testing, training local researchers, field measurement.

Funding: The authors wish to thank the Multi-Donor Trust Fund for Sustainable Logistics (MDTD-SL) administrated by the World Bank, CGIAR-A4NH Flagship Food Systems for Healthier Diets, and the KB-22 theme "Global food and nutrition security" of Wageningen UR funded by the Dutch Ministry of Agriculture, Nature and Food Quality (grant KB-22-002-010) for funding this study.

Acknowledgments: Thanks also goes to Frits Blessing, Peace Eruore Quadt (N-N-Solutions), Olalekan Emmanuel Akinwekomi and Thompson Ogunsanmi, both from the International Fertilizer Development Centre, for local support in Nigeria in design and execution of this project.

Conflicts of Interest: The authors declare no conflict of interest. The founding sponsors had no role in the design of the study, in the collection, analyses, or interpretation of data, in the writing of the manuscript, and in the decision to publish the results.

\section{References}

1. Lall, S.V.; Henderson, J.V.; Venables, A.J. Africa Cities. Opening Doors to the World; International Bank for Reconstruction and Development, the World Bank: Washington, DC, USA, 2017.

2. United Nations. Transforming our World: The 2030 Agenda for Sustainable Development Resolution A/RES/70/1; General Assembly of the United Nations: New York, NY, USA, 2015.

3. FAO. Global Food Losses and Food Waste-Extent, Causes and Prevention; Food and Agricultural Organization of the United Nations: Rome, Italy, 2011.

4. Sheahan, M.; Barrett, C.B. Review: Food loss and waste in sub-saharan Africa. Food Policy 2017, 70, 1-12. [CrossRef] [PubMed]

5. Affognon, H.; Mutungi, C.; Sanginga, P.; Borgemeister, C. Unpacking postharvest losses in sub-saharan Africa: A meta-analysis. World Dev. 2015, 66, 49-68. [CrossRef]

6. Sibomana, M.S.; Workneh, T.S.; Audain, K. A review of postharvest handling and losses in the fresh tomato supply chain: A focus on sub-saharan Africa. Food Secur. 2016, 8, 389-404. [CrossRef]

7. Ika, L.A. Project management for development in Africa: Why projects are failing and what can be done about it. Proj. Manag. J. 2012, 43, 27-41. [CrossRef]

8. Robinson, J.A.; Torvik, R. White elephants. J. Public Econ. 2005, 89, 197-210. [CrossRef]

9. Donovan, J.; Franzel, S.; Cunha, M.; Gyau, A.; Mithöfer, D. Guides for value chain development: A comparative review. J. Agribus. Dev. Emerg. Econ. 2015, 5, 2-23. [CrossRef]

10. Mohan, G. Participatory development: From epistemological reversals to active citizenship. Geogr. Compass 2007, 1, 779-796. [CrossRef]

11. Cornwall, A. Beneficiary, Consumer, Citizen: Perspectives on Participation for Poverty Reduction; Swedish International Development Cooperation Agency: Stockholm, Sweden, 2002.

12. Dell'Era, C.; Landoni, P. Living lab: A methodology between user-centred design and participatory design. Creat. Innov. Manag. 2014, 23, 137-154. [CrossRef]

13. Morgan, R.M.H.; Hunt, S.D. The commitment-trust theory of relationship marketing. J. Mark. 1994, 58, $20-38$. 
14. Grubben, G.; Klaver, W.; Nono-Womdim, R.; Everaarts, A.; Fondio, L.; Nugteren, J.A.; Corrado, M. Vegetables to combat the hidden hunger in Africa. Chron. Horticult. 2014, 54, 24-32.

15. Adeoye, I.B.; Adegbite, O.O.; Fashogbon, A.E.; Layade, A.A. Consumer purchasing behavior for tomatoes. Int. J.Veg. Sci. 2016, 22, 259-265. [CrossRef]

16. Leke, A.; Fiorini, R.; Dobbs, R.; Thompson, F.; Suleiman, A.; Wright, D. Nigeria's Renewal: Delivering Inclusive Growth in Africa's largest Economy; McKinsey Global Institute, McKinsey \& Company: Michigan, NY, USA, 2014.

17. Bolarin, F.M.; Bosa, S.O. Post-harvest losses: A dilemma in ensuring food security in Nigeria. J. Nat. Sci. Res. 2015, 5, 151-154.

18. Ibeawuchi, I.I.; Okoli, N.A.; Alagba, R.A.; Ofor, M.O.; Emma-Okafor, L.C.; Peter-Onoh, C.A.; Obiefuna, J.C. Fruit and vegetable crop production in Nigeria: The gains, challenges and the way forward. J. Biol. Agric. Healthc. 2015, 5, 194-202.

19. Muhammad, R.H.; Hionu, G.C.; Olayemi, F.F. Assessment of postharvest knowledge of fruit and vegetable farmers in Garun Mallam L.G.A. of Kano, Nigeria. Int. J. Dev. Sustain. 2012, 1, 510-515.

20. Adepoju, A.O. Post-harvest losses and welfare of tomato farmers in Ogbomosho, Osun State, Nigeria. J. Stored Prod. Postharvest Res. 2014, 5, 8-13.

21. Ugonna, C.U.; Jolaoso, M.A.; Onwualu, A.P. Tomato value chain in Nigeria: Issues, challenges and strategies. J. Sci. Res. Rep. 2015, 7, 501-515. [CrossRef] [PubMed]

22. Brown, J.; Isaacs, D.; The World Café Community. The World Café: Shaping Our Futures through Conversations that Matter; Barrett-Koehler Publishers, Inc.: San Francisco, CA, USA, 2005.

23. Katzy, B.R.; Pawar, K.; Thoben, K.D. Editorial: A living lab research agenda. Int. J. Prod. Dev. 2012, $17,1-7$.

24. Eriksson, M.; Niitamo, V.P.; Kulkki, S.; Hribernik, K.A. Living labs as a multi-contextual R\&D methodology. In Proceedings of the 12th International Conference on Concurrent Enterprising: Innovative Products and Services through Collaborative Networks, ICE 2006, Milan, Italy, 26-28 June 2006.

25. Følstad, A. Living labs for innovation and development of information and communication technology: A literature review. Electr. J. Virtual Org. Netw. 2008, 10, 99-131.

26. Tan, Y.H.; Bjørn-Andersen, N.; Klein, S.; Rukanova, B. Accelerating Global Supply Chains with It-innovation: Itaide Tools and Methods; Springer: Berlin/Heidelberg, Germany, 2011.

27. CGIAR, F.; KM4Dev; UNICEF; UNDP. The Knowledge Sharing Toolkit. Available online: http:/ / www. kstoolkit.org/The+World+Cafe (accessed on 6 March 2017).

28. WorldCafe. Guide to the World Cafe Method. Available online: http://www.click4it.org/images/a/a5/ World.pdf (accessed on 8 June 2017).

29. Adeoye, I.B.; Odeleye, O.M.O.; Babalola, S.O.; Afolayan, S.O. Economic analysis of tomato losses in Ibadan metropolis, Oyo State, Nigeria. African J. of Basic Appl. Sci. 2009, 1, 87-92.

30. Kok, M.G.; Dastoum, S.; Groot, J.J.; Plaisier, C.; Dijkxhoorn, Y.; van Wagenberg, C.P.A. White Paper on Measurement Protocol on Food Loss (Forthcoming); Wageningen Food \& Biobased Research: Wageningen, The Netherlands, 2018.

31. Idah, P.A.; Yisa, M.G.; Chukwu, O.; Morenikeji, O.O. Simulated transport damage study on fresh tomato (lycopersicon esculentum) fruits. Agric. Eng. Int. CIGR J. 2012, 14, 119-126.

(C) 2019 by the authors. Licensee MDPI, Basel, Switzerland. This article is an open access article distributed under the terms and conditions of the Creative Commons Attribution (CC BY) license (http://creativecommons.org/licenses/by/4.0/). 